Max-Planck-Institut für demografische Forschung

Max Planck Institute for Demographic Research

Konrad-Zuse-Strasse 1 - D-18057 Rostock · GERMANY

Tel +49 (0) 3812081 - 0; Fax +49 (0) 3812081 - 202;

http://www.demogr.mpg.de

MPIDR WORKING PAPER WP 2006-009

MARCH 2006

\title{
Objective sleep duration and health in elderly Russians
}

\author{
Maria Shkolnikova \\ Blake Aber \\ Maxine Weinstein \\ Lyubov' Kravtsova \\ Svetlana Shalnova \\ Vladimir Shkolnikov (shkolnikov@ demogr.mpg.de) \\ James W. Vaupel (jwv@demogr.mpg.de)
}

(C) Copyright is held by the authors.

Working papers of the Max Planck Institute for Demographic Research receive only limited review. Views or opinions expressed in working papers are attributable to the authors and do not necessarily reflect those of the Institute. 


\section{OBJECTIVE SLEEP DURATION AND HEALTH IN ELDERLY RUSSIANS}

Running Head: Objective sleep duration and health

Max Planck Institute for Demographic Research, Rostock, Germany

Maria Shkolnikova ${ }^{1}$, Professor, MD; Blake $\mathrm{Aber}^{2}$, Maxine Weinstein ${ }^{3}$, Professor, Lyubov'

Kravtsova $^{1}, \mathrm{MD}, \mathrm{PhD}$; Svetlana Shalnova ${ }^{4}$, Professor, MD; Vladimir Shkolnikov ${ }^{5}, \mathrm{PhD}$, and James

W. Vaupel $1^{5}$, Professor.

1 Center for Cardiac Arrhythmia, Moscow Institute of Pediatrics and Child Surgery;

2 Columbia University, New York;

3 Georgetown University, Washington DC;

4 State Research Centre for Preventive Medicine, Moscow;

5 Max Planck Institute for Demographic Research, Rostock, Germany.

Keywords: heart rate, Holter monitoring, mortality, aging, sleep duration, health 


\title{
OBJECTIVE SLEEP DURATION AND HEALTH IN ELDERLY
}

\section{RUSSIANS}

\begin{abstract}
Objectives - We examine the relationship between sleep duration and health in the high mortality context of Russia.

Methods - Night and daytime sleep durations are based on self-reports and 24-hour heart rate trends (Holter monitoring). The sample of 201 individuals (Holter data for 185) is drawn from the Moscow Lipid Research Clinics cohort, followed up since 1975-77. Field-work occurred in 200203.

Results - Although objective and reported mean sleep are similar, there are significant intraindividual differences. Significant associations are found between objective sleep and health: longer sleep corresponds to lower grip strength, poorer self-rated health and immediate recall, and higher mortality risk score. No significant relationships are found for subjective sleep. Conclusions - We provide the first evidence of an association between long sleep and worse health outcomes among elderly Russians. Predictive power increases if objective sleep measures are used, a consideration which is especially important in small studies.
\end{abstract}

